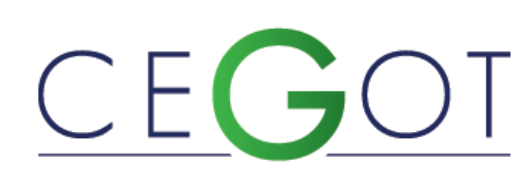

Centro de Estudos de Geografia e Ordenamento do Território
Geografia e Ordenamento do Território, Revista Eletrónica Centro de Estudos de Geografia e Ordenamento do Território http://cegot.org

CORREA, BIANCA

PPDSR/Universidade Estadual do Maranhão

Cidade Universitária Paulo VI - s/n- Tirirical-C. P. 09-CEP. 65055-970- São

Luís- Maranhão, Brasil

biancasampaio-c@hotmail.com

BARBOSA, ZULENE PPDSR/Departamento de Ciências Sociais da Universidade Estadual do Maranhão 65055-970, São Luís, Brasil

Zulene.mb@uol.com.br

\title{
O Programa de Aquisição de Alimentos - PAA: implicações socioeconômicas junto aos agricultores familiares da comunidade de Matinha - zona rural de São Luís
}

The Food Acquisition Program - PAA: socioeconomic implications farmers in the community of Matinha - São Luís.

Referência: Correa, Bianca; Barbosa, Zulene (2018). O Programa de Aquisição de Alimentos - PAA: implicações socioeconômicas junto aos agricultores familiares da comunidade de Matinha - zona rural de São Luís. Revista de Geografia e Ordenamento do Território (GOT), n. ${ }^{\circ} 14$ (setembro). Centro de Estudos de Geografia e Ordenamento do Território, p. 159177, dx.doi.org/10.17127/got/2018.14.006

\section{RESUMO}

Este trabalho apresenta como se deu a construção do PAA no âmbito das políticas públicas de segurança alimentar e nutricional para a agricultura familiar nos governos Lula e Dilma (2003 a 2014) e a inserção socioeconômica (organização e as atividades produtivas), dos agricultores familiares de Matinha - Maracanã, localizada na zona rural de São Luís. Trata-se de uma reflexão cujo objetivo consiste em examinar quais as implicações socioeconômicas deste programa sobre as atividades produtivas dos agricultores familiares de Matinha. Apresenta ainda como esses agricultores se reconhecem no processo de comercialização, as modificações registradas nas unidades produtivas quanto à retomada e ampliação dos cultivos tradicionais e na diversificação produtiva.

Palavras-chave: Agricultura Familiar. Segurança Alimentar. PAA. Estado. Desenvolvimento local.

\section{ABSTRACT}

This paper presents the construction of the PAA in the context of the public policies of food and nutritional security for family agriculture in the Lula and Dilma governments (2003 to 2014) and the socioeconomic insertion (organization and productive activities) Matinha Maracanã, located in the rural area of São Luís. This is a reflection that aim to examine the socioeconomic implications of this program on the productive activities of the family farmers of Matinha. It also shows how these farmers recognize themselves in the marketing process, the changes in the productive units regarding the resumption and expansion of traditional crops and the diversification of production. 
Keywords: Family farming. Food Safety. PAA. State. Local development.

\section{Introdução}

Este texto apresenta um debate a respeito do problema alimentar no mundo em que estão envolvidas, pelo menos, duas grandes dimensões, ambas compreendendo considerável leque de aspectos: uma é aquela em que se procura reconhecer a alimentação como um direito natural e inalienável do indivíduo; a outra dimensão é a que discute como garantir esse direito, como fazer com que as pessoas tenham acesso aos alimentos, ou seja, a dimensão da segurança alimentar e nutricional.

Nesta perspectiva, vale ressaltar a situação do Estado do Maranhão quanto à segurança alimentar que, segundo os dados do PNAD (2004 e 2009), permite comparar a evolução da posição do Maranhão, nesse campo, com a situação do Brasil e das Grandes Regiões. A pesquisa demonstrou que, no Brasil, em 2004, 34,9\% dos domicílios (18,0 milhões de domicílios) possuíam pelo menos um morador em situação de insegurança alimentar, mas no Nordeste o percentual era de 53,6\% (7,1 milhões) e, no Maranhão chegava a 69,1\% (987 mil). Em 2009, em termos percentuais, todas as esferas de análises apresentaram redução no percentual de domicílios com insegurança alimentar, mas o Estado do Maranhão mostrou a menor intensidade na redução, chegando, inclusive, em termos absolutos, a aumentar o total de domicílios com pelo menos um morador em situação de insegurança alimentar grave. Em 2009, o percentual de domicílios em situação de insegurança alimentar no Brasil era de 30,2\% (1,1 milhão); no Nordeste, o percentual era de 46,1\% (7,1 milhões) e, no Maranhão eram 64,6\% (1,7 milhões).

Dessa forma, na última década, estados e municípios têm trabalhado com modelos estruturantes pautados nos conceitos de Segurança Alimentar e Nutricional como eixos estratégicos de desenvolvimento com inclusão social. Nessas proposições das políticas alimentares brasileiras, alguns programas passam a ser vistos como possibilidade de concretização dessas mudanças, como por exemplo, o Programa de Aquisição de Alimentos (PAA). 
O instrumental metodológico da pesquisa contemplou o uso de técnicas de investigação de caráter qualitativo. Desse modo, a busca pelas respostas aos questionamentos suscitados iniciou-se a partir do levantamento bibliográfico (campo teórico e conceitual), que norteou a análise para compreender cientificamente a realidade. A partir da construção de um arcabouço teórico, que possibilitou analisar e refletir acerca da realidade da comunidade de Matinha, buscou-se fontes secundárias produzidas pelos institutos de pesquisa, a exemplo do Instituto Maranhense de Estudos Socioeconômicos e Cartográficos - IMESC e do Instituto Brasileiro de Geografia e Estatística - IBGE; monografias, dissertações e teses; artigos e dados dos órgãos oficiais como o Ministério do Desenvolvimento Social e Combate à Fome MDS, dados da Companhia Nacional de Abastecimento e da Secretaria Municipal de Segurança Alimentar- SEMSA.

Além das fontes secundárias o estudo considerou fontes primárias que se originaram da observação in loco, ação de grande importância para perceber a realidade para além dos relatórios e estatísticas apresentados tanto pelos órgãos oficiais, como pelos sujeitos sociais envolvidos no PAA. Nesse sentido, privilegiou-se a técnica da entrevista, tendo sido considerada fundamental para analisar as diferentes perspectivas da comunidade de Matinha e o poder local que a comunidade busca construir.

No entanto, objetiva-se analisar quais as implicações socioeconômicas do PAA sobre as atividades produtivas dos agricultores familiares da comunidade de Matinha a fim de identifica-los como se reconhecem no processo de comercialização concernente ao referido programa, identificar quais as modificações nas unidades produtivas quanto à retomada e ampliação dos cultivos tradicionais e a diversificação produtiva e ainda quais as tendências do PAA quanto a novas perspectivas para o desenvolvimento da atividade agrícola.

\section{O PAA no contexto dos governos Lula e Dilma}

Na primeira metade do século $X X$, surgiram os primeiros debates a respeito da fome no Brasil. Os estudos do médico, geógrafo e historiador pernambucano Josué de Castro, mas 
especificamente em seu livro "A Geopolítica da Fome", coloca a fome como um fenômeno geográfico universal.

Contemporaneamente, foi em 1986 que a segurança alimentar apareceu como objetivo que define as ações de uma política de abastecimento alimentar. No final da década de 1980, a abertura comercial, com o predomínio de políticas neoliberais voltadas para a estabilização monetária aumentou as desigualdades sociais.

No Brasil, ainda que recém-saído do Mapa da fome, existem cerca de 23 milhões de brasileiros desnutridos FAO (Paulillo, 2002). Mesmo com a suficiente oferta de produção de alimentos nos países desenvolvidos, a fome ainda persiste em vários lugares do mundo. 0 Brasil, por exemplo, desde os anos 1970, mesmo com sucessivos recordes de safra, a desigualdade social não diminuiu, ao contrário, só aumentou. No caso da desigualdade de renda, em 2000 a distância entre a renda dos $20 \%$ mais pobres e dos $20 \%$ mais ricos do Brasil foi de 33 vezes, segundo o IPEA (Istituto de Pesquisas Econômicas e Aplicadas). Os $20 \%$ da população brasileira mais pobre recebem apena $2 \%$ da renda, segundo o Banco Mundial. Como comparação, o percentual é de 3,1\% na Argentina e de 4\% na Bolívia.

O problema da fome no Brasil passou para a agenda pública a partir de 2003 , vinculada ao modelo econômico vigente atrelado ao poder aquisitivo de compra dos alimentos e não necessariamente à falta de alimentos. Neste contexto, o Programa Fome Zero começou a ser delineado como parte de uma Política de Segurança Alimentar e Nutricional para a população brasileira, cujo princpial objetivo é a garantia do direito à alimentação, que deve ser assegurado pelo Estado.

Logo, neste contexto da política de segurança alimentar, o Programa Fome Zero pode ser apontado como o grande marco através do qual se aglutina um conjunto de programas de intervenção, tanto de caráter imediato quanto de natureza estrutural, implementados por meio de instrumentos de políticas públicas como o PAA. Dessa forma, o PAA - Programa de Aquisição de Alimentos, não emerge sozinho, mas articulado em um conjunto, como um dos braços de força da macroestrutura de amparo e reestruturação social denominada Fome Zero e concebido como estratégia do governo federal referente ao mercado institucional de alimentos. O PAA, além da articulação entre produção, comercialização e consumo possui uma filosofia que indica claramente a quem deve ser estendido as ações de amparo, ou 
seja, àquelas famílias que ainda são atingidas pela fome, em maior ou menor grau. Observase que um dos requisitos para a produção de alimentos direcionada à parcela da população em estado de insegurança alimentar é que esta ação promova a inclusão social, favorecendo os agricultores ainda não totalmente incluídos no sistema produtivo.

Garantir acesso aos alimentos é a primeira assertiva e remete à filosofia de todo o programa Fome Zero. Corroborando com esta afirmativa, o PAA promove a inclusão social no campo, o que é feito por meio do fortalecimento da agricultura familiar. Dessa forma, o Programa objetiva acelerar o rompimento do ciclo da pobreza no espaço rural, onde os agricultores, sem condições de comercializar, não produzem o suficiente e, consequentemente não têm como escoar a produção a.

\subsection{O PAA como política pública de fortalecimento da agricultura familiar}

Como política pública, o Programa de Aquisição de Alimentos - PAA resultou de dois importantes debates concretizados na década de 1990: a segurança alimentar e nutricional e o reconhecimento por parte do governo federal da necessidade de fortalecer a agricultura familiar com base no Pronaf (Programa de Fortalecimento da Agricultura Familiar). Esquecida na década neoliberal, esta proposta encontrou novos espaços durante o governo Lula em 2003, sendo uma das ações incluídas na estratégia de Segurança Alimentar e Nutricional (SAN), articulada ao Programa Fome Zero. Este programa foi instituído pela Lei № 10.696, de 2 de julho de 2003, regulamentada pelo Decreto № 4.772 de 2 de julho de 2003, alterado pelo Decreto № 5.783, de 15 de agosto de 2006. O PAA apresenta-se em cinco modalidades, destacadas no quadro 1 a seguir: 


\begin{tabular}{|c|c|c|}
\hline Sigla & Título & Ementa \\
\hline CDLAF & $\begin{array}{ll}\text { Compra } & \text { direta local } \\
\text { da } & \text { agricultura } \\
\text { familiar } & \end{array}$ & $\begin{array}{l}\text { Promove a articulação entre a produção de agricultores familiares } \\
\text { e as demandas locais de suplementação alimentar e nutricional no } \\
\text { desenvolvimento da economia local, no fortalecimento da } \\
\text { agricultura familiar e na geração de trabalho e renda no campo. É } \\
\text { operada pelos Governos Estaduais e Prefeituras Municipais. }\end{array}$ \\
\hline CDAF & $\begin{array}{l}\text { Compra Direta da } \\
\text { Agricultura Familiar }\end{array}$ & $\begin{array}{l}\text { Possibilita a aquisição de alimentos pelo Governo Federal, a } \\
\text { preços de referência, a produtores organizados em grupos formais } \\
\text { (cooperativas e associações). É operada pela CONAB (COMPANHIA } \\
\text { NACIONAL DE ABASTECIMENTO). }\end{array}$ \\
\hline CAEAF & $\begin{array}{lr}\text { Compra } & \text { Antecipada } \\
\text { Especial } & \text { da } \\
\text { Agricultura } & \text { Familiar } \\
- & \text { Doação } \\
\text { Simultânea } & \\
\end{array}$ & $\begin{array}{l}\text { Visa adquirir alimentos de agricultores familiares organizados em } \\
\text { grupos formais (cooperativas e associações), com vista à doação } \\
\text { para instituições governamentais ou não governamentais que } \\
\text { desenvolvam trabalhos publicamente reconhecidos de } \\
\text { atendimento às populações em situação de insegurança alimentar } \\
\text { e nutricional. É operada pela CONAB. }\end{array}$ \\
\hline $\begin{array}{l}\text { CPR - } \\
\text { Estoque }\end{array}$ & $\begin{array}{l}\text { Formação de } \\
\text { Estoques pela } \\
\text { Agricultura Familiar }\end{array}$ & $\begin{array}{l}\text { Visa adquirir alimentos da safra vigente, próprios para consumo } \\
\text { humano, oriundos de agricultores familiares organizados em } \\
\text { grupos formais para a formação de estoques em suas próprias } \\
\text { organizações. É operada pela CONAB. }\end{array}$ \\
\hline IPCL & $\begin{array}{ll}\text { Incentivo } & \text { à } \\
\text { produção } & \mathrm{e} \\
\text { consumo de leite } & \end{array}$ & $\begin{array}{l}\text { Propiciar o consumo de leite às famílias que se encontram em } \\
\text { situação de insegurança alimentar e nutricional e incentivar a } \\
\text { produção familiar. É operada pelos Governos Estaduais. }\end{array}$ \\
\hline
\end{tabular}

Quadro 1 - Modalidades do Programa de Aquisição de Alimentos

Fonte: Ministério do Desenvolvimento Social e Combate à Fome (MDS), 2007.

Dados recentes da CONAB (2017) apontam que o total de recursos provenientes do SEAD/MDS - Secretaria Especial de Agricultura Familiar e do Desenvolvimento Agrário (SEAD) e do Ministério de Desenvolvimento Social, repassados em 2016, totalizou $\mathrm{R} \$$ 201.315.754,82. Esse recurso foi distribuído entre as modalidades Compra com Doação Simultânea - CDS (R\$ 183,9 milhões), Aquisição de Sementes (R\$ 4 milhões), Apoio à Formação de Estoques pela Agricultura Familiar - CPR Estoque (R\$ 9,5 milhões) e recursos que envolvem a operacionalização do Programa (R\$ 2,7 milhões), além das despesas com impostos. Os valores utilizados nas modalidades operacionalizadas pela CONAB possibilitaram a comercialização de 88.120 toneladas de alimentos produzidos por 29.318 agricultores familiares organizados em Cooperativas ou Associações que apresentaram 845 projetos. 
O Gráfico a seguir permite comparar a evolução dos investimentos feitos nas modalidades do PAA no período de 2009 a 2016.

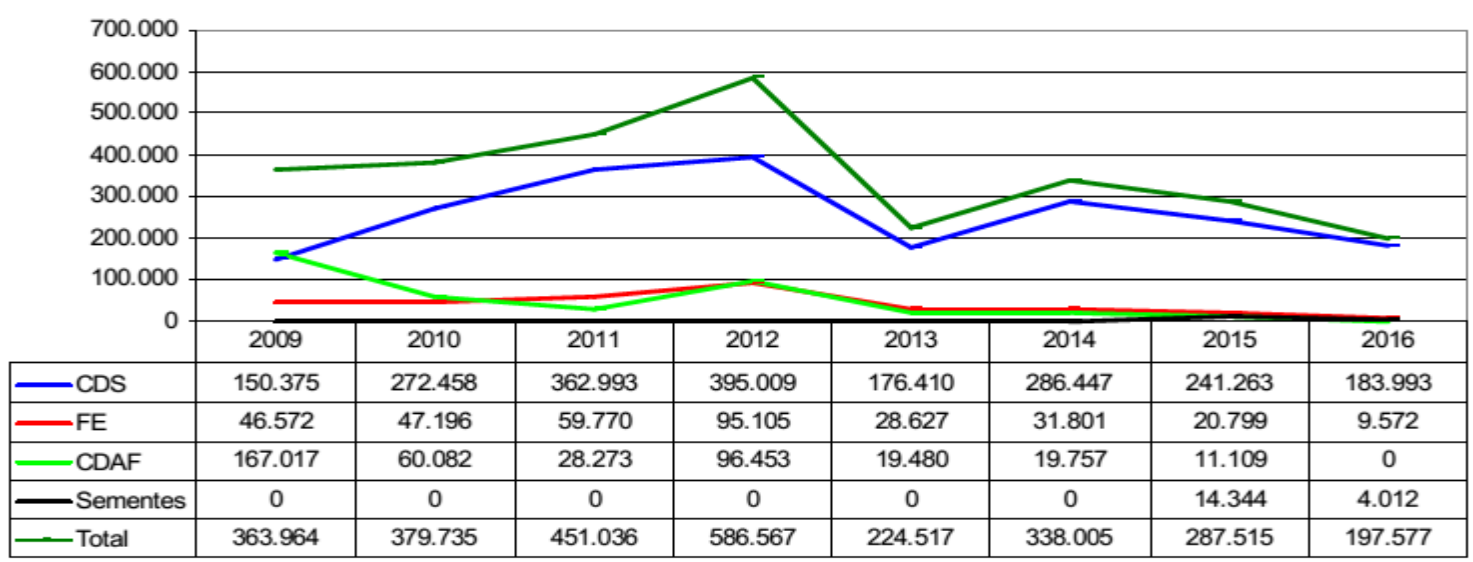

Gráfico 1 - Evolução das modalidades do PAA de 2009 a 2016 (valor em mil reais) Fonte: CONAB, 2017.

Os dados do gráfico 1 demonstram que o melhor desempenho do PAA em 2016 está concentrado na modalidade Compra com Doação Simultânea, operacionalizado com recursos do MDS. O êxito dessa modalidade em relação às demais se deve ao seu desenho e às suas características, ao possibilitar a comercialização de produtos característicos da agricultura familiar, como hortaliças, frutas, doces, biscoitos caseiros, dentre outros, que são adquiridos por meio de Organizações Fornecedoras e entregues às Unidades Recebedoras (CONAB, 2017).

Segundo os dados do documento do estado pode-se verificar a evolução do PAA no período de 2012 a 2016, conforme demonstra o quadro 2:

\begin{tabular}{|c|c|c|c|}
\hline \multicolumn{5}{|c|}{ Número de municípios adesos } \\
\hline 2012 & 2013 & 2014 & 2015 \\
\hline 35 & 69 & 104 & 104 \\
\hline \multicolumn{5}{|c|}{ Número de municípios comercializando } \\
\hline 2012 & 2013 & 2014 & 2015 \\
\hline 5 & 13 & 36 & 2015 \\
\hline \multicolumn{5}{|c|}{ Número estimado de indivíduos vulneráveis atendidos } \\
\hline 2012 & 2013 & 2014 & 2015 \\
\hline 6.301 & 31.884 & 45.000 & 3.504 \\
\hline 2012 & 2013 & 2014 & 2015 \\
\hline 140 & 625 & 2.794 & $12.272 .900,02$ \\
\hline \multicolumn{5}{|c|}{ Número de agricultores atendidos } \\
\hline 2012 & 2013 & 2014 \\
\hline $156.932,76$ & $1.679 .261,00$ & $6.055,021,15$ & \\
\hline
\end{tabular}


Quadro2. Evolução do PAA no Maranhão 2012 a 2016.

Fonte: Documento do governo do estado, 2016.

A partir desses dados verificou-se que houve um aumento do recurso aplicado no PAA e número de agricultores familiares atendidos.

\subsection{O PAA como instrumento de desenvolvimento local}

Sabe-se que a agricultura familiar é essencial para o desenvolvimento econômico das pequenas e médias cidades brasileiras. Logo, as intervenções do Estado para a melhoria da agricultura familiar, como foi o caso da criação do Pronaf e demais ações e políticas públicas implementadas, é de grande importância. Sobre este tema, Brose (1999) afirma que o desenvolvimento local, baseado na agricultura familiar, depende fundamentalmente da intervenção estatal regulando as assimetrias do mercado através de políticas públicas. Se deixada à própria sorte frente às forças do mercado, a agricultura familiar se transforma em alvo fácil de monopólios e intermediários que se apropriam do valor agregado da produção.

Cabe destacar, a natureza de classe do Estado, que intervém através da elaboração de políticas públicas como é o caso do PAA no intuito de fotalecer a agricultura familiar. Segundo Poulantzas (1977), o Estado capitalista ao exercer a sua dominação de classe, não o faz sempre do mesmo modo, assumindo formas políticas particulares correspondentes a modos distintos de organização da dominação de classe. Para o autor, uma função precípua do Estado capitalista é criar as condições jurídico-políticas adequadas necessárias à reprodução das relações de produção capitalistas, o que faz na medida em que desempenha uma dupla função: a) individualiza os agentes de produção mediante a sua conversão em pessoas jurídicas, em sujeitos individuais; b) neutraliza a tendência à ação coletiva decorrente do caráter socializado do processo de trabalho determinando, desse modo, a predominância no produtor direto, a tendência ao isolamento decorrente do caráter privado assumido pelos trabalhos nesse processo. Este tipo de Estado, ao ocultar o seu caráter de classe, apresenta-se como a,

... encarnação da vontade popular do povo nação, sendo este institucionalmente fixado como conjunto de cidadãos, indivíduos, cuja unidade o Estado capitalista representa e que tem como substrato real o efeito de isolamento que as relações sociais econômicas do modo de produção capitalista manifestam. (POULANTZAS, 1977, p. 129) 
Trata-se de perceber o caráter de classe do Estado, apreendendo-o teoricamente a partir dos vínculos que ele mantém com as relações de produção, o que implica, no limite, compreedê-lo como um Estado que é classista sem, contudo, inscrever explicitamente este caráter em sua estrutura e tão pouco ser necessariamente controlado de modo direto por qualquer classe social (ALMEIDA, 2009).

A perspectiva aqui é localizar a ação do Estado no local como parte do espaço regional, mas que também se articula com outras escalas como a transnacional. Existe, pois, quando se pensa o desenvolvimento sócio espacial regional a necessidade de compreender os processos sociais que se articulam a partir do local. No caso do PAA, os governos locais assumem um papel importante na implementação dessas políticas apesar destas serem formuladas no âmbito do governo federal, cabendo ao local propriamente a sua execução. Segundo Feitosa (2011) nos últimos anos as políticas de desenvolvimento local têm assumido um papel de destaque na promoção do desenvolvimento econômico em decorrências das transformações nos processos produtivos.

Levando-se em conta as especificidades das diferentes realidades, o conceito de desenvolvimento passou por vários questionamentos, que trouxeram alternativas a ele próprio - nesse caso, o desenvolvimento local ${ }^{1}$. No atual contexto do neoliberalismo a partir dos anos 1990 outras concepções de desenvolvimento emergem, entre elas a de desenvolvimento local. Para muitos estudiosos surgem daí outras alternativas ao desenvolvimento, que, para Franco (2002), tiveram seus primeiros sinais no final dos anos 1980, quando as pessoas começaram a questionar o mito do primado econômico e quando se estabeleceu um novo padrão de relação estado-sociedade.

Nesse momento, ações e projetos relacionados ao combate à pobreza rural e à desigualdade social, implementados principalmente por entidades não governamentais e governos municipais ou em parcerias com programas federais, são impulsionados a partir da Constituição de 1988, na perspectiva de descentralização.

Nesse sentido várias políticas associadas ao discurso de desenvolvimento local, a exemplo da criação dos Territórios da Cidadania no Brasil associada à ideia de fortalecimento das

\footnotetext{
${ }^{1}$ Entendido por Jesus (2007), como um processo de inclusão social que mobiliza pessoas e instituições buscando a transformação da economia e da sociedade, criando oportunidades de trabalho e de renda superando dificuldades para favorecer a melhoria das condições de vida da população local.
} 
potencialidades entre municípios vizinhos, com características semelhantes, onde são estabelecidas discussões com diversos segmentos sociais, elegendo-se prioridades para ações e projetos.

Nesta perspectiva, ao tratarmos de desenvolvimento local, referimo-nos não só ao desenvolvimento econômico, mas também ao desenvolvimento social e sustentável ambientalmente. Por isso, é preciso realizar investimentos em capital humano, social e natural, além daqueles correspondentes ao capital econômico e financeiro. O enfoque do desenvolvimento local para alguns autores possui uma visão integrada dessas dimensões, a partir de um desenho que é realizado nos próprios territórios e com a efetiva participação dos atores locais.

Entretanto, como defende Lemos e Lima (2014) para que essas estratégias estejam inseridas na perspectiva do desenvolvimento local, é necessário que, além de considerar as especificidades territoriais, econômicas e de produção, leve-se em conta a motivação conjunta que inclua o respeito às diferenças sociais e culturais e que tenha como foco o processo participativo.

O desenvolvimento local seria, nesse sentido, um exercício de cidadania, não se restringindo ao atendimento das demandas sociais básicas. Ele visa a geração de renda e a diminuição das desigualdades sociais, transformando as dificuldades e os obstáculos em oportunidades (Campanhola e Silva, 2000). Foi isso que se levou a refletir sobre o desenvolvimento local. Nas entrevistas realizadas na comunidade de Matinha, quanto à inclusão produtiva grande parte dos agricultores relataram que o PAA possibilitou aumentar a quantidade da produção, embora não tenha havido a diversificação dos produtos

O cenário em foco explicitou que o desempenho na unidade de produção dos agricultores familiares não subtraiu a quantidade da produção, mas proporcionou o aumento desta, o que se incorpora à análise de Chayanov (1974), de que a administração do trabalho e tamanho da área utilizada pelo agricultor deve ser determinada pela necessidade da família, logo a satisfação deve ser limitada pelo trabalho desprendido na produção.

O PAA, segundo relato possibilitou ampliar as relações para fora da comunidade como para feiras livres local onde também os agricultores comercializam seus produtos. Estas, antes identificadas a um modelo arcaico de relações mercantis cuja extinção inevitável 
dependeria do ritmo de expansão das grandes redes varejistas, atualmente voltam a ocupar os espaços públicos de inúmeras cidades.

A partir do referencial analítico da teoria do desenvolvimento local e dos relatos de campo, no início a implementação do PAA significou para os agricultores o alcance de uma situação (provisória) com um certo "empoderamento", visto que, em função de estarem organizados, puderam ter acesso aos recursos dos programas e passaram a vender a sua produção por um preço justo. Com isso, pode-se afirmar que eles passaram a deter um certo "poder" no tocante à superação das relações sociais de exploração a que estavam submetidos no processo de comercialização com os atravessadores.

Assim, tendo em vista que o programa visa fortalecer a agricultura familiar, a partir da "Inclusão produtiva", vale ressaltar que a "inclusão produtiva" se tornou um mantra para a ação do Estado e da própria sociedade civil organizada. Mas esta expressão genérica assume significados distintos, na decorrência dos desacordos sobre o espaço de manobra e as alternativas que existem para os "pobres rurais" (Nierdele 2017). A autora enfatiza que as políticas públicas incorporaram a noção de "inclusão produtiva" e as contradições que ela suscita: Pronaf, Bolsa Família, Pronatec, Luz para Todos, PAA, Plano Brasil Sem Miséria. Afirma serem estes programas uma referência para a inclusão produtiva, dito de outro modo, parece fazer desta noção, a expressão de um entendimento comum sobre a forma e o conteúdo da ação pública.

Segundo Nierdele (2017), a política de desenvolvimento territorial (PRONAT-PTC) é um exemplo forte que reforça a inclusão produtiva como estratégia voltada para os agricultores pobres. Por outro lado, revela como o termo comporta uma pluralidade de significados, que respondem a distintos referenciais de desenvolvimento.

Enquanto alguns se associam a uma lógica modernizante centrada na capacidade dos agricultores em oferecer respostas produtivas convencionais (apostando na melhoria da capacidade tecnológica e empreendedora de um agricultor profissionalizado), outros sustentam experiências alternativas que sugerem a emergência de um novo rural multifuncional e pós-produtivista (NIERDELE, 2017, p. 170).

A inclusão produtiva se tornou assim uma espécie de plano-padrão na ação pública na luta para superar a miséria, assegurar a renda, sustentar os níveis de emprego, fortalecer as comunidades, reduzir o peso das políticas sociais, e até salvar os recursos naturais de um suposto (e criticável) "círculo vicioso da pobreza". Assim, a inclusão produtiva tornou-se a 
expressão de como algumas sociedades modernas, organizadas pela ética do "trabalho eficaz", defiram a única opção legítima para a inserção social dos seus indivíduos.

Constata-se, portanto, que são diversas as definições de desenvolvimento local. Mas em sua maioria incorporam a ideia comum de que este tipo de desenvolvimento não se restringe à noção de crescimento econômico e que o local não é um mero espaço físico, mas, ao contrário, ele é uma construção social - condicionador e condicionado por e a partir das ações dos seus atores e comunidades.

\subsection{A Modalidade de compra e doação simultânea em São Luís: mediações político- institucionais}

A modalidade compra e doação simultânea estabelece uma intrínseca relação entre produção, compra e consumo efetivada por meio da SEMSA (Secretaria de Segurança Alimentar), a qual compra os alimentos dos agricultores e os doa para as famílias de baixa renda atendida nos CRAS de vários bairros de São Luís. Como afirmara Marx (2008) a produção sempre aparece como o ponto inicial e o consumo, como ponto final; a distribuição e a troca aparecem como o centro, que por isso mesmo é dúplice, já que a distribuição é determinada como momento que emana da sociedade e a troca como momento que emana dos indivíduos.

Sob a perspectiva da produção de alimentos, algumas estratégias como os circuitos locais de produção de alimentos são capazes de viabilizar a reconexão (produção-consumo) sob outra racionalidade produtiva a exemplos da produção de alimentos orgânicos ou agroecológicos fomentados pela intervenção do Estado - mediante programas e políticas públicas - como o PAA (Bezerra e Schneider, 2012). Desse modo, a circulação, seja na produção, seja no consumo de alimentos no âmbito local, potencializa ou oportuniza, também, outras relações sociais, econômicas e alimentares que vão além da simples resistência ao processo de desconexão do sistema agroalimentar.

O PAA ao articular a produção de alimentos ao consumo local, respeitando a sazonalidade, a proximidade, os atributos de qualidade, o saber-fazer local, a diferenciação etc. contrapõese ao modelo de produção assentado em grandes corporações, que valoriza a distância, a padronização, a durabilidade dos produtos, a impessoalidade e subordina o tempo e o lugar 
à acumulação de capital (Triches, Froehlich, 2008). Sobretudo na modalidade de "Compra para Doação Simultânea", produtores e consumidores encontram-se articulados e compreendem a importância que um tem para o outro.

Schmitt (2005) chama a atenção para o fato de que o PAA sinaliza um novo estágio no que se refere às políticas de fortalecimento da agricultura familiar, sobretudo porque atua na comercialização dos produtos desta categoria social.

Além da garantia de mercado, o programa apresenta outras contribuições. Como citam Delgado et al. (2005), este tem colaborado para a recuperação dos preços regionais havendo casos em que o simples anúncio da compra pública de dado produto é suficiente para elevar a sua cotação. Em algumas situações, o mercado local absorve a produção antes mesmo das compras públicas serem efetuadas, dispensando a efetivação das mesmas (caso das compras para a formação de estoques). Isso contribui para a autonomia dos agricultores em relação aos "atravessadores"/"intermediários" ao assegurar a mediação entre consumo e produção. Ou seja, para os agricultores de Matinha, a relação institucional que estabelecem com a SEMSA tem contribuído com famílias, principalmente na questão da logística de entrega de alimentos, pois estas famílias não precisam fazer a entrega dos produtos ponto a ponto conforme pode ser observado em entrevista realizada com umas das agricultoras cadastradas no PAA: "A gente não precisa de atravessador, a gente passa os produtos por um preço justo e sem contar que incentiva também a produção coisa que ficou extinta durante muitos anos aqui no Brasil, a questão da produção". (Entrevista, a1, 2017).

Outra questão que facilita a comercialização da produção na comunidade é a adequação dos produtos para a entrega, quanto à embalagem, rotulagem e adequação dos alimentos conforme a demanda. Na comunidade de Matinha os agricultores entregam os seus produtos na Associação de Moradores e Produtores Rurais (central de recebimento dos alimentos não só dos agricultores desta comunidade, mas de outras como Laranjeiras) e a SEMSA faz o processo de embalagem das cestas de alimentos para a entrega aos beneficiados consumidores - as famílias de baixa renda.

A Associação de Moradores é o local da organização coletiva dos agricultores - onde ocorre a entrega dos alimentos que serão destinados ao PAA nas seguintes etapas: primeiro faz-se a embalagem dos alimentos, depois os alimentos são pesados para então serem 
distribuídos. As figuras abaixo demostram este processo de operacionalização do PAA na associação de moradores dos produtores rurais de Matinha.

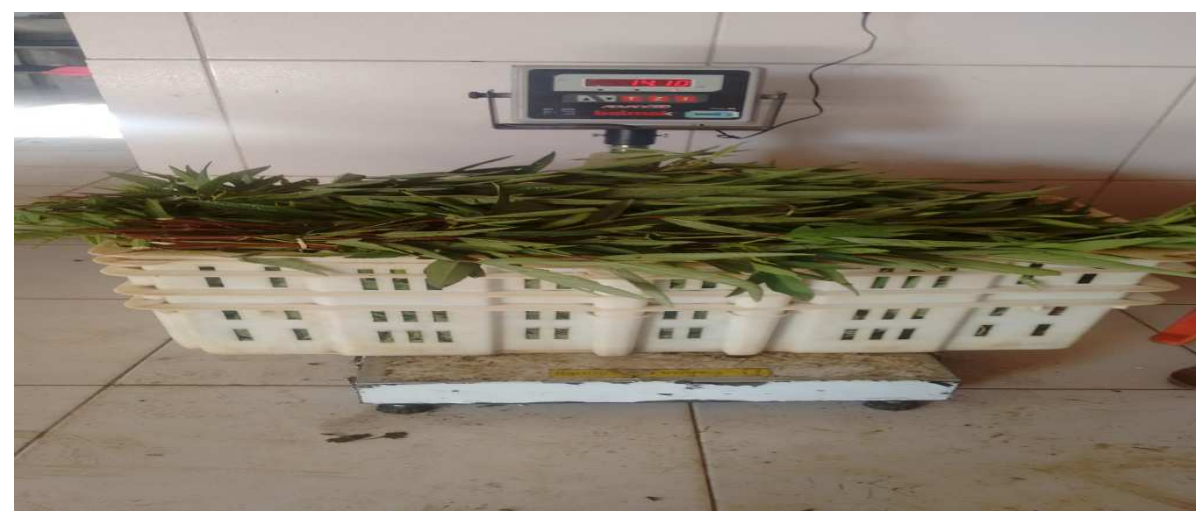

Figura 1: alimento sendo pesado para ser embalado. Fonte: Própria tirada em 19/07/2017.

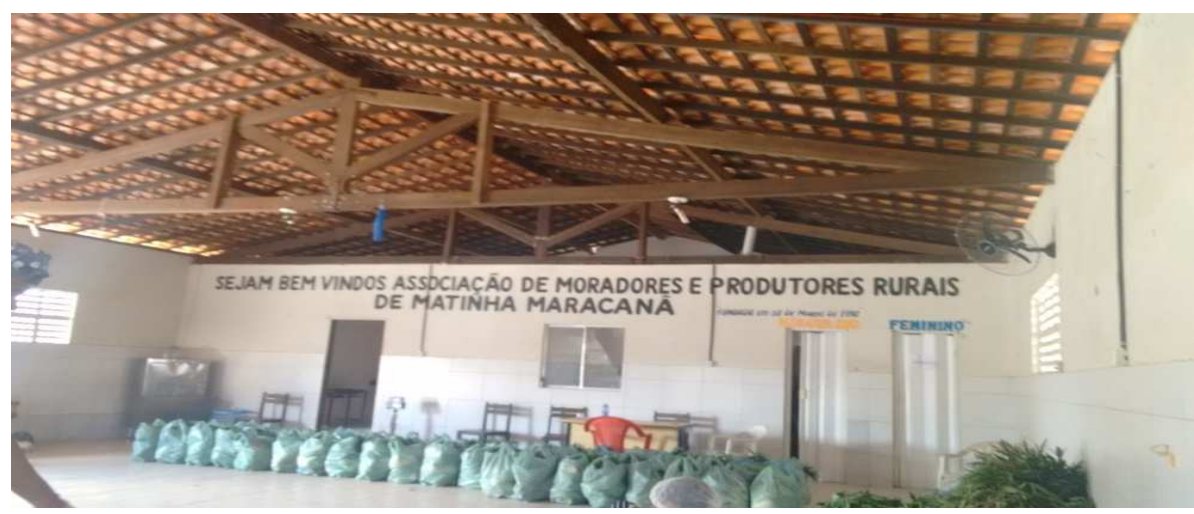

Figura 2: alimentos embalados pela SEMSA para serem doados nos CRAS. Fonte: Própria tirada em 19/07/2017.

Existe ainda relação institucional com referência à parte fiscal e a outras atividades burocráticas que envolvem a comercialização desses alimentos. A Associação de Moradores da Comunidade de Matinha se torna um instrumento de diálogo entre os agricultores familiares e os órgãos públicos, facilitando a dinâmica da comercialização. Nesse processo alguns profissionais atuam diretamente no contato com as prefeituras e o órgão do estado, elaborando os projetos e adequando a comercialização conforme a demanda apresentada.

No caso do processo de comercialização dos alimentos com a prefeitura existe um Termo de Recebimento e conforme afirma o coordenador logístico do PAA, o Senhor Marcos Vinícius dos Anjos, este termo funciona como nota fiscal. Na SEMSA as informações referentes aos agricultores e alimentos são lançadas no sistema do governo federal e depois é emitida uma 
nota fiscal da Secretaria da Fazenda para então liberar o pagamento aos agricultores. Este termo de recebimento é necessário para que o agricultor entregue seus alimentos e também possa receber o pagamento.

Quanto à organização dos agricultores para a entrega dos alimentos a Senhora Maria da Conceição Almeida relata que antes do programa, existia a associação, porém não havia uma organização para a comercialização de alimentos. A SEMSA ao estipular um limite de produtos a ser entregue, uma vez por semana, estimulou uma maior organização desses agricultores no processo de comercialização dos seus produtos.

Cabe ressaltar que o Programa de Aquisição de Alimentos foi criado no município de São Luís em 2013, por meio do termo de adesão № 0526/2013, com a participação do Estado do Maranhão e do governo federal para auxílio na execução do programa. O município executa o programa de acordo com as modalidades e metas pactuadas por meio de Planos Operacionais.

O Programa conta ainda com a SEMAPA (Secretaria Municipal de Agricultura, Pesca e Abastecimento) para a sua execução. De acordo com informações disponibilizadas pela SEMSA, o PAA em São Luís é implementado na Modalidade Doação Simultânea, sendo responsabilidade da SEMAPA o cadastramento dos produtores, a garantia da assistência técnica e a realização do monitoramento das etapas de produção e certificação de atestado de qualidade dos produtos.

Já à SEMSA cabe a gestão, o recebimento e distribuição dos alimentos, além da prestação de contas dos produtos junto ao Ministério de Desenvolvimento Social e Combate à Fome MDS. Nesta modalidade Doação Simultânea, a SEMSA recebe do próprio produtor os alimentos e entrega ao beneficiário, sem necessidade de armazenamento. Os agricultores podem vender, individualmente, até $\mathrm{R} \$ 6.500,00$ (seis mil e quinhentos reais) por unidade familiar/ano. O total dos recursos para a primeira etapa foi de $\mathrm{R} \$ 1.650 .000,00$.

De acordo com as informações transmitidas pela coordenadora do PAA, na primeira etapa do programa 300 agricultores foram cadastrados e distribuídos $377.412 \mathrm{~kg}$ de alimentos entre hospitais e associações inscritas nos CRAS, público beneficiado. Na segunda etapa iniciada em 2017, o valor investido no PAA pelo MDS diminuiu totalizando um valor de 1.155.000,00 reais e 178 agricultores cadastrados, havendo, pois, uma diminuição do 
número de agricultores atendidos. Foi distribuído até o mês de maio de 2017, o total de 47 toneladas de alimentos, considerando que nesta segunda etapa o público beneficiado foram apenas os CRAS, totalizando 2.160 famílias, isto é, 8.640 pessoas aproximadamente.

A coordenadora do PAA nos relatou que, no município de São Luís, o PAA está vinculado a 20 CRAS nos bairros: Anjo da Guarda, Sol e Mar, Cidade Operária, Vila Bacanga, Forquilha/Cohab, Anil, Bairro de Fátima, Centro, Cidade Olímpica, Coroadinho, Estiva, Janaína, João de Deus, Vila Nova, Vicente Fialho/Vinhais, São Raimundo, São Francisco, Maracanã, Liberdade, Vila Palmeira/Bequimão/Rio Anil. Acrescentou que os agricultores fornecedores dos alimentos a estes CRAS pertencem às seguintes comunidades: Matinha, Cassaco, Cajupary, Itapera, Quebra-Pote, Vila Nova República, Laranjeiras, Igaraú, Arraial, Terra do Rumo, Calembe, Coquilho I e II, Tajipuru, São Raimundo do Motor e Mato Grosso.

Observou-se em entrevistas realizadas com os beneficiados do CRAS do Anjo da Guarda que eles veem o Programa como um meio que trouxe mais qualidade de vida no sentido de ajuda-los a consumir alimentos saudáveis, tendo em vista que os consumidores são pessoas carentes, ou seja, que possuem baixa renda. Todavia, quanto à entrega dos alimentos uma beneficiária consumidora BC1 entrevistada salientou que "o Programa é ótimo! Assim, tá fazendo um ano que a gente recebeu se fosse uma vez por mês seria melhor né". (Entrevista, BC1, 2017).

\section{Considerações finais}

A luta contra a fome no mundo tem mobilizado diferentes organismos internacionais através do tempo. O surgimento da Declaração Mundial da Alimentação, em conferência realizada em Roma no ano de 1996, coincidiu com um apelo enfático por parte do Diretor Geral da FAO para que se empreendesse uma "corrida contra o relógio", a fim de reduzir a metade o número de desnutridos até o ano 2015.

Nesta perspectiva, o Estado tem atuado através da implementação de políticas públicas voltadas para a promoção da Segurança Alimentar e o combate a fome. No Brasil, Fiori 
(2006) inicia a sua discussão sobre o papel do estado brasileiro atravessando os distintos governos e as suas transformações desde a década de 1930. O papel do Estado é colocado como tendo sido fundamental, seja através do investimento e da produção direta, seja através da ação indireta e financiamento interno e externo. O que Fiori (2006), coloca é que o Estado teve o papel de aglutinador da acumulação industrial no Brasil.

A discussão de Fiori (2006) aborda a questão agrária brasileira, a problemática da (ausência de) reforma agrária, a questão do Nordeste e o semiárido brasileiro, as populações específicas vulneráveis, o agronegócio e a agricultura familiar (pequena propriedade tradicional), temas abordados intensamente pelo CONSEA. Portanto, o PAA nos reporta às discussões relacionadas à pobreza no Brasil, à fome, à disponibilidade de alimentos, à segurança alimentar e nutricional e às relações de comercialização da agricultura familiar. Outro elemento de discussão questiona a forma como essas políticas têm contribuído para o desenvolvimento local e o papel das instituições de Assistência Técnica e Extensão Rural no apoio ao segmento populacional da agricultura familiar para que este melhor participe e se beneficie das políticas públicas.

Neste sentido, Tauk Santos (2002,) apud Lemos e Lima (2014), afirma que o desenvolvimento local tem levado a novos arranjos institucionais e ao estabelecimento de parcerias com os atores sociais sendo de responsabilidade da extensão rural contemporânea o papel de promover a articulação entre os atores envolvidos.

Pode-se concluir que em termos percentuais não houve uma grande transformação e que a insegurança alimentar não pode ser atribuída à falta de alimentos, mas sim às condições que assegurem o seu acesso, seja na forma de programas de transferência de renda, seja via produção de alimentos para o autoconsumo, tanto no campo quanto na cidade.

No que diz respeito ao objetivo geral deste trabalho, verificou-se que o PAA contribui para o fortalecimento da agricultura a partir do processo de comercialização, em que o agricultor tem para além do mercado livre, como as feiras, por exemplo, a oportunidade de ampliar a sua diversidade e o quantitativo de produção, no caso para o programa, ou seja, para o mercado institucional. Com a venda dos produtos ao mercado institucional os produtos começaram a ser mais conhecidos pela comunidade, de uma maneira geral, o que fez com que novos mercados se abrissem aos agricultores familiares, ampliando, desta forma, os 
níveis de comercialização da agricultura familiar na comunidade. Porém, os limites de valor impostos para a compra dos produtos e a qualidade estabelecida pelo PAA para a comercialização da produção da agricultura familiar foram identificados como os principais gargalos do programa. Apesar dessas limitações, verificou-se o grande interesse demonstrado pelos agricultores familiares de Matinha em continuar participando do programa, pois percebem a melhoria da receita familiar desta participação.

A discussão que se deu na sociedade civil foi amadurecendo e, devido à característica de permeabilidade do estado brasileiro, encontrou no governo sob a presidência de Luís Inácio Lula da Silva espaço para se efetivar em ações de política pública. No caso do PAA, a permeabilidade se deu de forma bastante específica. Diferentemente das conclusões dos estudos de Marques (2000), por exemplo, onde o autor identifica influência de grupos que, institucionalmente, estão fora do governo, na rede do PAA.

O PAA traz ainda elementos em sua concepção que apontam para um redirecionamento do entendimento sobre o papel que a agricultura familiar exerce no desenvolvimento da sociedade brasileira, principalmente nas perspectivas de desenvolvimento mais equitativo, com a incorporação de setores excluídos da economia e com a valorização da atuação dos agricultores familiares enquanto atores. Com base neste arcabouço de elementos que subsidiam a análise dos dados, se pode concluir que o PAA, por não ser uma política de fato, apenas um programa governamental, cumpre os objetivos com que foi proposto e tem um peso significativo no fortalecimento da agricultura familiar e no seu desenvolvimento sustentável, porém, necessita de avanços no tocante ao reconhecimento da sua importância e na fundamentação e criação de uma política pública institucionalizada.

\section{Referências bibliográficas}

ALMEIDA, Flávio Lúcio Rodrigues de. De Volta à Ilha de Tranquilidade em Meio a Um Oceano Revolto? Limites da democracia liberal brasileira. In Lutas Sociais. São Paulo,№ 23. 2o semestre, 2009.

BROSE, M. Agricultura familiar, desenvolvimento local e políticas públicas. Santa Cruz do Sul: Edunisc, 1999.

BEZERRA, Islandia; SCHNEIDER, Sergio. Produção e Consumo de Alimentos: o papel das políticas públicas na relação entre o plantar e o comer. Volume 15 - Número 20- Jan/Jun 2012.

CHAYANOV, A. V. La organización de la unidad económica campesina. Buenos Aires: Nueva Visión, 1974. CAMPANHOLA, Clayton; SILVA, José Graziano da. DESENVOLVIMENTO LOCAL E A DEMOCRATIZAÇÃO DOS 
ESPAÇOS RURAIS. Cadernos de Ciência \& Tecnologia, Brasília, v.17, n.1, p.11-40, jan./abr. 2000.

Companhia Nacional de Abastecimento. Programa de Aquisição de Alimentos - PAA: resultados das ações da Conab em 2016. Brasília: Conab, 2017.

FRANCO, Augusto de. Pobreza \& Desenvolvimento Local. Brasília, AED (Agência de Educação para o Desenvolvimento)/ARCA Sociedade do Conhecimento, 2002.

FEITOSA. Cid Olival. A importância da inovação para o desenvolvimento econômico local. Economia política do desenvolvimento. Maceió, vol. 4, n. 12, p. 29-50, set./dez. 2011.

FIORI, José Luís. A esquerda e o desenvolvimentismo. 2006.

JESUS, Paulo de. Desenvolvimento Local e Sustentabilidade - algumas considerações conceituais e suas implicações em projetos de pesquisa. In: PEDROSA, Ivo; MACIEL FILHO, Adalberto; ASSUNÇÃO, Luis Márcio (orgs). Gestão de desenvolvimento local sustentável. Recife: EDUPE, 2007.

LEMOS, Silvana Maria de; LIMA, Irenilda de Souza .O Programa de Aquisição de Alimentos (PAA) como política pública para a agricultura familiar e o desenvolvimento local. Oikos: Revista Brasileira de Economia Doméstica, Viçosa, v. 25, n.1, p. 069-092, 2014.

MARX, Karl. Contribuição à crítica da economia política. tradução e introdução de Florestan Fernandes. 2. ed.São Paulo : Expressão Popular, 2008.

NIEDERLE, Paulo Andre. Afinal, que Inclusão produtiva? A contribuição dos novos mercados alimentares In: DELGADO, Guilherme Costa; BERGAMASCO, Sonia Maria Pessoa Pereira (Orgs). Agricultura familiar brasileira: desafios e perspectivas de futuro. Secretaria Especial de Agricultura Familiar e do Desenvolvimento Agrário Brasília, 2017.

PAULILLO, L. F. Et al. Reestruturação agroindustrial, políticas públicas e segurança alimentar regional. São Carlos: Edufscar, 2002.

POULANTZAS, Nicos. Poder Político e Classes Sociais. São Paulo: Martins Fontes, 1977.

SCHMITT,C.J. Aquisição de alimentos da agricultura familiar: integração entre política agrícola e segurança alimentar e nutricional. Revista de Política Agrícola. Ano XIV, n.2, p. 78-88, abr./mai./jun., 2005.

TRICHES, R.M.; FROEHLICH, E. Reconectando o consumo à produção: a aquisição de produtos da agricultura familiar para a alimentação escolar. In: /l Colóquio Agricultura Familiar e Desenvolvimento Rural. Porto Alegre: PGDR, 2008. 